\section{OP0114 BENEFICIAL EFFECTS OF RISEDRONATE TREATMENT ON BMD AND VERTEBRAL FRACTURE RISK IN MEN ON GC THERAPY}

${ }^{1} \mathrm{P}$ Thompson, ${ }^{2} \mathrm{RF}$ Laan, ${ }^{3} \mathrm{G}$ Weryha, ${ }^{4} \mathrm{C}$ Hrncirik. ${ }^{1}$ Department of Rheumatology, Poole Hospital (NHS Trust), Poole, UK; ${ }^{2}$ Department of Rheumatology, Academisch Ziekenhuis, Nijmegen, NB, The Netherlands; ${ }^{3}$ Department of Rheumatology, CHU de Nancy, Nancy, France; ${ }^{4}$ Department of Rheumatology, Procter \& Gamble Pharmaceuticals, Mason, $\mathrm{OH}$, USA

\subsection{6/annrheumdis-2001.635}

Background Of the 518 patients enrolled in studies of patients initiating or on maintenance of glucocorticoid (GC) therapy (Prevention: less than 3 months on GC therapy and Treatment: greater than 6 months GC therapy), 186 were men. There were 77 men in the Prevention study and 109 in the Treatment study. The mean ages and lumbar spine T-scores were 59.5, - 0.38 for the Prevention study and 56.2 and ?1.67 for the Treatment study respectively.

Objectives

Methods Patients were randomised to receive placebo, or risedronate (RIS) $2.5 \mathrm{mg}$, or RIS $5 \mathrm{mg}$ daily for 1 year in both studies. Patients were supplemented with elemental calcium $500 \mathrm{mg} /$ day or elemental calcium $1 \mathrm{~g} /$ day and vitamin D $400 \mathrm{IU} /$ day. Most men in the studies were taking GC therapy for either rheumatoid arthritis $(38 \%)$ or lung disease $(22 \%)$.

Results RIS $5 \mathrm{mg}$ significantly increased BMD or prevented bone loss at both the spine and the hip in men (Table 1 Year BMD Mean (SE)\% Change from Baseline in Men Taking Glucocorticoids). $23 \%$ (9 out of 38) of placebo patients had a new vertebral fracture compared with $5 \%$ in the risedronate 2.5 and 5 $\mathrm{mg} /$ day treated group (3 out of 58). The vertebral fracture risk reduction was $82 \%(\mathrm{p}=0.008)$ for pooled risedronate doses.

\begin{tabular}{llll}
\hline \multicolumn{1}{l}{ Abstract OP0114 Table 1} & & \\
\hline & $\begin{array}{l}\text { Treatment } \\
\text { Group } \\
\text { Control [n] }\end{array}$ & $\begin{array}{l}\text { Treatment } \\
\text { group } \\
\text { RIS } 2.5 \mathrm{mg}[\mathrm{n}]\end{array}$ & $\begin{array}{l}\text { Treatment } \\
\text { Group } \\
\text { RIS } 5 \mathrm{mg}[\mathrm{n}]\end{array}$ \\
\hline $\begin{array}{l}\text { Lumbar Spine (Prevention } \\
\text { Study) }\end{array}$ & $-3.4(0.8)^{*}[19]$ & $0.3(1.3)[9]$ & $0.8(0.6)^{\wedge}[24]$ \\
$\begin{array}{l}\text { Femoral Neck (Prevention } \\
\text { Study) }\end{array}$ & $-3.3(1.1)^{\star}[20]$ & $-0.7(1.7)[9]$ & $1.5(1.0)^{\wedge}[24]$ \\
$\begin{array}{l}\text { Trochanter (Prevention Study) } \\
\text { Lumbar Spine (Treatment }\end{array}$ & $-3.4(0.9)^{\star}[20]$ & $-0.3(1.1)[9]$ & $1.5(0.8)^{\wedge}[24]$ \\
$\begin{array}{l}\text { Study) } \\
\text { Femoral Neck (Treatment }\end{array}$ & $-0.2(1.0)[24]$ & $-0.7(0.8)[25]$ & $2.1(0.7)^{\star}[25]$ \\
$\begin{array}{l}\text { Study) } \\
\text { Trochanter (Treatment Study) }\end{array}$ & $0.5(1.4)[24]$ & $0.4(0.8)[25]$ & $2.6(0.5)^{\star}[25]$ \\
\hline
\end{tabular}

${ }^{*} p$ less than or equal to 0.05 vs. baseline; $\wedge p$ less than or equal to 0.05 vs. control.

Conclusion In summary, these studies demonstrate that risedronate is effective in preventing bone loss in men recently on glucocorticoids and can increase BMD in men on long term glucocorticoid therapy.

\section{OP0116 VERTEBRAL DEFORMITIES ARE ASSOCIATED WITH QUANTITATIVE ULTRASOUND VARIABLES IN RHEUMATOID ARTHRITIS A STUDY OF 198 FEMALE PATIENTS}

${ }^{1} \mathrm{RE}$ Orstavik, ${ }^{1} \mathrm{G}$ Haugeberg, ${ }^{1} \mathrm{TK}$ Kvien, ${ }^{2} \mathrm{~F}$ Lilleaas, ${ }^{3} \mathrm{~A}$ Hoiseth. ${ }^{1}$ Department of Rheumatology; ${ }^{2}$ Department of Radiology, Diakonhjemmet Hospital; ${ }^{3}$ Department of Rheumatology, Sentrum Institute of Radiology, Oslo, Norway

10.1136/annrheumdis-2001.636

\section{Background}

Objectives Earlier studies have suggested that bone quality might be reduced in RA patients, and lead to a lower fracture threshold regarding DEXA measurements. Quantitative ultrasound (QUS) may give additional information about bone quality not captured by DEXA. The aim of this study was to examine the relationship between vertebral deformities (VD), and bone mass measured by DEXA and QUS in female RA patients.

Methods Lateral radiographs of the spine were obtained from 198 female RA patients born 1926 or later (mean age (SD) 63.3 (6.7) yrs, mean disease duration 16.7 (10.3) yrs), recruited from a population based county RA register. Vertebral deformities were measured by an experienced radiologist (AH), using a standardised semiquantitative method described by Genant, and classified as mild, moderate or severe (a reduction in any of the vertebral heights of $20-25 \%, 25-40 \%$ and more than $40 \%$, respectively). QUS was measured for both heels (Lunar Achilles $+)$, providing speed of sound (SOS), broadband ultrasound attenuation (BUA) and Stiffness Index (SI), a parameter computed from the two above. The patients underwent BMD measurements by DEXA (Lunar Expert) at the femoral neck, total hip and lumbar spine (L2-L4).

Results The total number of deformities was 127 (63 moderate or severe). Thirty-nine patients (19.7\%) had at least two mild or one moderate/severe fracture. Mean values (SD) for SOS was $1484.2 \mathrm{~m} / \mathrm{s}$ (35.6), BUA $98.27 \mathrm{~dB} / \mathrm{MHz}$ (15.07) and SI 61.14\% (19.14), mean values of T- and Z-score were ?2.43 (1.20) and ? 0.97 (1.12) respectively. Mean BMD (SD) for femoral neck was $0,807 \mathrm{gm} / \mathrm{cm}^{2}(0.140)$, total hip $0.840 \mathrm{gm} / \mathrm{cm}^{2}(0.150)$ and L2L4 $1.050 \mathrm{gm} / \mathrm{cm}^{2}(0.199)$, corresponding T- and Z-scores were ? $1.44(1.17) /-0.24(0.14),-1.33(1.25) /-0.36(1.09)$ and ?1.25 (1.66)/0.20 (1.55). Correlations between SI and DEXA at the femoral neck, total hip and L2-L4 were $0.56,0.63$ and 0.44 respectively.

Table 1 shows the results of the bivariate analysis of the different QUS measurement values.

In logistic regression analysis, applying a model using various demographic and disease variables, a Z-score less than ?1SD for Stiffness showed an independent association with vertebral deformities.

\begin{tabular}{llll}
\multicolumn{4}{l}{ Abstract OP0116 Table 1} \\
\hline & VD negative & VD positive & p-value \\
\hline BUA (dB/MHz) & 100.5 & 89.03 & $<0.001$ \\
SOS $(\mathrm{m} / \mathrm{s})$ & 1489.4 & 1463.8 & $<0.001$ \\
SI $(\%)$ & 64.09 & 49.10 & $<0.001$ \\
T-score $<-2.5$ QUS* & $43.4 \%$ & $76.9 \%$ & $<0.001$ \\
T-score $<-2.5$ DEXA* $^{*}$ & $11.8 \%$ & $27.8 \%$ & 0.03
\end{tabular}

*Computed from Stiffness Index ** At the total hip, results for femoral neck and L2-L4 were non-significant. 
Conclusion SOS, BUA and Stiffness were all strongly associated with vertebral deformities in RA patients. QUS might be an independent predictor for vertebral deformities, but this need to be evaluated in larger, prospective studies.

\section{SAT0150 MISSED DIAGNOSIS AND TREATMENT OF OSTEOPOROSIS IN ELDERLY PATIENTS WITH HIP FRACTURE}

${ }^{1} \mathrm{~J}$ Iborra, ${ }^{2} \mathrm{E}$ Pagès, ${ }^{2} \mathrm{~S}$ Rodríguez, ${ }^{2} \mathrm{~A}$ Cuxart. ${ }^{1} I+D$ Novartis; ${ }^{2}$ Rehabilitation Medicine, Vall $d^{\prime}$ Hebron Hospitals, Barcelona, Spain

10.1136/annrheumdis-2001.637

Background Physicians can recognise and treat osteoporosis before the occurrence of fracture. Unfortunately, there is ample evidence that clinicians have not heard or heeded the message that condition is treatable, and that selected patients, particularly those who have already suffered a fracture, should be counselled to received preventive therapy. ${ }^{1}$ Epidemiologic studies have demonstrated that a history of osteoporotic fracture places a patient at very high risk of future fractures. ${ }^{2}$

Objectives The purpose of this study was to investigate whether elderly patients admitted to our hospital with a principal diagnosis of hip fracture had a prior diagnosis of osteoporosis or a previous osteoporotic fracture and their previous prescribed treatment.

Methods We performed a prospective chart review of all elderly $(>=65$ years) patients admitted with the diagnosis of acute hip fracture in a public hospital in Barcelona, Spain, from January 1, 1999, to December 31, 2000. Data were collected by interviewing each patient immediately after their fracture with a structured questionnaire including patient age, sex, residence, the number, type and causes of fractures, as well as previous history of osteoporosis or osteoporotic fracture, and previous treatment for osteoporosis.

Results A total of 741 patients were included. Mean age was 81.54 (range 65-103) and $74.14 \%$ were women. Six hundred seven $(81.91 \%)$ patients were admitted from their own home. Thirty $(4.05 \%)$ patients had other associated fracture; the most common was a subcapital humeral fracture, which occurred in 13 patients. There were 447 (60.32\%) extracapsular fractures. A fall was the most common cause of hip fracture $(94.87 \%$ of cases). A prior diagnosis of osteoporosis was recorded in 50 (6.74\%) patients; of them 23 (46\%) were using calcium, vitamin $\mathrm{D}$, alendronate or calcitonin. A history of hip, vertebral, wrist or another osteoporotic fracture, was recorded in 221 (29.82\%) patients but only $18(8.14 \%)$ were using any treatment for osteoporosis. Moreover 66 patients $(8.91 \%)$ had suffered from more than one fracture. Forty-seven patients (6.34\%) were on long term systemic steroids treatment for 6 months or more; ten $(21,28 \%)$ were treated with calcium, vitamin $\mathrm{D}$, alendronate or calcitonin. Eight patients admitted with a hip fracture in 1999 had a second hip fracture in 2000 , but only two were receiving preventive therapy.

Conclusion Rates of utilisation of pharmacological treatment for osteoporosis were low. Prior diagnosis of osteoporosis was the condition that implied a better (less than half) preventive treatment, but clinicians dis not consistently initiate treatment for skeletal fragility after one or more fractures had occurred.

\section{REFERENCES}

1 Bauer DC. Osteoporotic fractures: ignorance is bliss?. Am J Med. 2000;109:3389
2 Cummings SR, et al. Risk factors for hip fracture in white women. Study of Osteoporotic Fractures Research Group. N Engl I Med. 1995;332:767-73

\section{SAT0151 DIAGNOSTIC CRITERIA OF OSTEOPOROSIS IN PATIENTS WITH RA}

${ }^{1} \mathrm{~S}$ Sohen, ${ }^{1} \mathrm{M}$ Kamiya, ${ }^{1} \mathrm{M}$ Ueno, ${ }^{2} \mathrm{H}$ Kikuchi, ${ }^{3} \mathrm{~T}$ Nonaka, ${ }^{3} \mathrm{~T}$ Hamanishi. ${ }^{1}$ Orthopaedic Surgery and Rheumatology, Nara Hospital, Kinki University School of Medicine, Ikoma; ${ }^{2}$ Orthopaedic Surgery, Sakai Hospital, Kinki University School of Medicine, Sakai; ${ }^{3}$ Orthopaedic Surgery, Kinki University School of Medicine, Osakasayama, Japan

10.1136/annrheumdis-2001.638

Background We reported that generalised bone loss was observed in rheumatoid arthritis (RA), especially in post menopausal patients and closely correlate with the activity of RA. On the other hand, glucocorticoids are used in the treatment of active patients with RA. Osteoporosis and related fractures are one of the most serious adverse effects of glucocorticoids.

Objectives Recommendations for the prevention and treatment of glucocorticoid-induced osteoporosis were proposed by American College of Rheumatology and UK Consensus Group. On the other hand, the diagnosis of osteoporosis in patients with RA was usually made by the diagnostic criteria of primary osteoporosis. The purpose of the present study was to clarify the validity of using the diagnostic criteria of primary osteoporosis for the diagnosis of osteoporosis in RA.

Methods The cutoff values were defined as the value by which the subjects with spine fracture were discriminated from those without spine fracture efficiently in terms of sensitivity and specificity. The subjects and measurement of bone mineral density (BMD) were follows: number of subjects; 256 (47 with vertebral fracture, 219 without vertebral fracture), age of subjects (mean $\pm \mathrm{SD}$ ); fracture group $64.2 \pm 9.0$ years, non fracture group $59.8 \pm 10.9$ years, measured site (type of machine); lumbar spine (QDR). Patients treated with glucocorticoid were follows: number of subjects; 103(29 with vertebral fracture, 74 without vertebral fracture), Age of subjects (mean $\pm \mathrm{SD}$ ); fracture group $65.1 \pm 12.5$ years, non fracture group $54.2 \pm 13.6$ years.

Results The cutoff value of all patients with RA was $0.711 \mathrm{~g} / \mathrm{cm}^{2}$ (T score: $-2.6, \%$ of the young adult mean (\%YAM): 70\%). This value was almost same as the cutoff value (BMD: $0.708, \%$ YAM:70\%) of osteoporosis proposed by the Japanese diagnostic criteria of primary osteoporosis and as the cutoff value (T score below -2.5) of osteoporosis proposed by the WHO diagnostic criteria. On the other hand, the cutoff value in the patients treated with daily doses of $7.5 \mathrm{mg}$ or more prednisolone was $0.812 \mathrm{~g} / \mathrm{cm}^{2}$ (T score: $-1.7, \%$ YAM: $80 \%$ ). This value was almost same as the value of osteopenia by the Japanese diagnostic criteria (\%YAM below 80\%) and by the WHO diagnostic criteria (T score below -1.0).

Conclusion These results supported the validity of using the diagnostic criteria of primary osteoporosis for the diagnosis of osteoporosis in patients with RA. But, in patients treated with daily doses of $7.5 \mathrm{mg}$ or more prednisolone, we have to start the treatment for preventing bone loss, if the patients are diagnosed for osteopenia using the diagnostic criteria of primary osteoporosis. 